\title{
The impact of surgical outcome after pancreaticoduodenectomy in elderly patients
}

\author{
Yasuhiro Ito ${ }^{1 *}$, Takeshi Kenmochi ${ }^{1}$, Tomoyuki Irino ${ }^{1}$, Tomohisa Egawa ${ }^{1}$, Shinobu Hayashi ${ }^{1}$, Atsushi Nagashima ${ }^{1}$ and
} Yuko Kitagawa ${ }^{2}$

\begin{abstract}
Background: The elderly population has increased in many countries. Indications for cancer treatment in elderly patients have expanded, because surgical techniques and medical management have improved remarkably. Pancreaticoduodenectomy (PD) requires high-quality techniques and perioperative management methods. If it is possible for elderly patients to withstand an aggressive surgery, age should not be considered a contraindication for PD. Appropriate preoperative evaluation of elderly patients will lead to their safer management. The purpose of the present study was to evaluate the safety of PD in patients older than 75 years and to show the influence of advanced age on the morbidity and mortality associated with this operation.
\end{abstract}

Patients and methods: Subjects were 98 patients who underwent PD during the time period from April 2005 to April 2011. During this study, 31 patients were 75 years of age or older (group A), and the other 67 patients were less than 75 years old (group B). Preoperative demographic and clinical data, surgical procedure, pathologic diagnosis, postoperative course and complication details were collected prospectively and they were analyzed in two group.

Results: There was no statistical difference between patient groups in terms of gender, comorbidity, preoperative drainage, diagnosis, or laboratory data. Preoperative albumin values were lower in group $A(P=0.04)$. The mean surgical time in group A was $408.1 \pm 73.47 \mathrm{~min}$. Blood loss and blood transfusion were not significantly different between both groups. There was no statistical differences in mortality rate $(P=0.14)$, morbidity rate $(P=0.43)$, and mean length of hospital stay $(P=0.22)$ between both groups.

Long-term survival was also no statistically significant difference between the two groups using the log-rank test $(P=0.10)$.

Conclusion: It cannot be ignored that the elderly population is getting larger. We must investigate the management of elderly patients after PD and prepare further for more experiences of PD. If appropriate surgical management is provided to elderly patients, we suggest that PD will lead to no adverse effects after surgery, and PD can be performed safely in elderly patients. We conclude that age should not be a contraindication to PD.

Keywords: Pancreaticoduodenectomy, Elderly patients, Outcome

\section{Background}

The elderly population has increased in many countries. Indications for cancer treatment in elderly patients have expanded, because surgical techniques and medical management have improved remarkably. However, given that the morbidity and mortality associated with surgical

\footnotetext{
* Correspondence: yasuito@ca3.so-net.ne.jp

'Department of Surgery, Saiseikai Yokohamashi Tobu Hospital, 3-6-1

Shimosueyoshi, Tsurumi-ku, Yokohama-shi, Kanagawa, 230-0012 Japan

Full list of author information is available at the end of the article
}

procedures are poorly defined in this population, the decision to perform an operation in an elderly patient can be difficult [1]. Therefore, surgeons must give this decision careful consideration. Pancreaticoduodenectomy (PD), which may cause considerable complications, including pancreatic fistula, intra-abdominal bleeding, intra-abdominal abscess, sepsis and organ failure, requires high-quality techniques and perioperative management methods. Though PD is performed in many hospitals, its associated morbidity and mortality rates are

\section{() Biomed Central}


high. In particular, pancreatic fistula still occurs in 5\% to $40 \%$ of patients, despite refinements in surgical techniques and perioperative management methods [2-5]. In spite of its high rate of morbidity, this aggressive surgery is considered curative. It has been suggested that patients who undergo PD appear to benefit from referral to a high-volume center [6-8]. If it is possible for elderly patients to withstand an aggressive surgery, age should not be considered a contraindication for PD [9]. Appropriate preoperative evaluation of elderly patients will lead to their safer management. In fact, it has been reported that PD can be performed safely in elderly patients [10-12].

The purpose of the present study was to evaluate the safety of PD in patients older than 75 years and to show the influence of advanced age on the morbidity and mortality associated with this operation.

\section{Methods \\ Protocol}

Subjects were 98 consecutive patients who underwent PD during the time period from April 2005 to April 2011. The final diagnoses of these patients were Pancreatic carcinoma $(\mathrm{n}=39)$, Cholangiocarcinoma $(\mathrm{n}=37)$, Ampullary carcinoma $(\mathrm{n}=8)$, Intraductal papillary mucinous neoplasm $(n=6)$, Duodenal carcinoma $(n=3)$, Gastric carcinoma $(\mathrm{n}=1)$, Duodenal invasion by colon carcinoma $(\mathrm{n}=$ $1)$ and Others $(n=3)$. The operative technique chosen for pancreatic anastomosis involved drainage of the pancreatic stump into an isolated loop of the jejunum with an endto-side, duct-to-mucosa anastomosis, including a pancreatic stent in all cases. Two techniques were applied in a strictly alternating way. As a result, the patients were allocated to two groups: (a) an internal stent group that underwent PD involving a pancreatic stump anastomosis to an isolated loop of the jejunum with an end-to-side, duct-to-mucosa anastomosis with an internal stent and (b) an external stent group that underwent PD with an external stent.

\section{Surgical technique}

Conventional or pylorus-preserving PD (PPPD) was performed at the discretion of the individual surgeon. Lymph nodes around the head of the pancreas, the common hepatic artery, and the hepatoduodenal ligament were dissected. Wedge or segmental resection of the portal vein or superior mesenteric vein was performed when the pancreatic head mass was inseparable from the vein. After resection, anastomoses were constructed to a single jejunal loop, which was repositioned up into the supra-mesocolic compartment in a retrocolic manner.

Pancreaticojejunal anastomosis was performed in an end-to-side fashion. The patients were allocated to the internal stent group and the external stent group. After pancreaticojejunal anastomosis, an end-to-side, single layer, interrupted hepaticojejunostomy without stenting was performed. The operation was completed with an end-to-side duodenojejunostomy with mechanical dilation of the pylorus $40 \mathrm{~cm}$ downstream from the pancreaticojejunostomy.

\section{Perioperative management}

Twenty-six patients underwent PD, and seventeen patients underwent substomach-preserving PD (SSPPD) with Child reconstruction. Fifty-five patients underwent PPPD with Traverso reconstruction. Pancreatic anastomosis after PD, SSPPD and PPPD was performed by duct-to-mucosal, end-to-side pancreaticojejunostomy in all enrolled patients.

Perioperative management was standardized. All patients received broad-spectrum antibiotics for two days and an $\mathrm{H} 2$ blocker (famotidine) during the entire postoperative hospital course. No prophylactic somatostatin or Octreotide was used. The nasogastric tube was removed on the first postoperative day when discharge was less than $500 \mathrm{ml}$. The volume of fluid drained from the peripancreatic drains and from the pancreatic duct was measured daily. Patients were kept nil per os for the first five postoperative days, after which the diet was gradually resumed if there was no evidence of delayed gastric emptying, pancreatic leakage or other intraabdominal complications. Total parenteral nutrition was used only in patients who could not tolerate a diet after postoperative day five. The peripancreatic drains were removed if there was no evidence of leakage. If there was evidence of leakage or suspicion of infective complications (fever, leukocytosis or purulent drain fluid), the peripancreatic drains were left in-situ, and a contrast computed tomography (CT) scan was performed to look for any intra-abdominal collection.

Patients were discharged with the pancreatic duct catheter in-situ, and this was removed at our outpatient clinic after the fourth postoperative week.

\section{Data collection}

Preoperative demographic and clinical data, surgical procedure, pathologic diagnosis, postoperative course and complication details were collected prospectively.

\section{Statistical analysis}

Continuous data are expressed as mean \pm standard deviation (SD). The $\chi 2$ test was used to compare qualitative parameters, and Student's t-test was used for quantitative parameters. Patient overall survival was evaluated using the Kaplan-Meier method and compared with the log-rank test. $\mathrm{P}<.05$ was considered significant. 


\section{Results}

\section{Patient characteristics}

PDs were performed in 98 patients at our institution between April 2005 and April 2011. During this study, 31 patients (31.6\%) were 75 years of age or older (group A), and the other 67 patients $(68.4 \%)$ were less than 75 years old (group B). There was no statistical difference between patient groups in terms of gender, comorbidity, preoperative drainage, diagnosis, or laboratory data (hemoglobin, total bilirubin, amylase, hemoglobin A1c). Preoperative albumin values were lower in group $A$ than in group $B$ $(\mathrm{P}=.04)$. Patient characteristics and preoperative laboratory datas according to age group are shown in Table 1. Of 90 total patients over 75 years that we saw, we decided not to perform surgery for 59 (65.6\%). PD was decided for all of the elderly patients for whom surgery could be performed. In our institution, the indication for PD is resectable cases, as well as younger patients. PD was performed in the absence of peritoneal or distant metastases and when a tumor was not locally advanced. Cases with limited invasion of a portal or superior mesenteric vein were considered to be resectable.

\section{Operative outcomes}

The 31 PDs (standard PD in 6 patients (19.4\%), SSPPD in 7 (22.6\%) and PPPD in 18 (58.1\%)) performed in group A included Cholangiocarcinoma in 15 (48.4\%) patients, Pancreatic adenocarcinoma in 8 (25.8\%), Ampullary carcinoma in 5 (16.1\%), Intraductal papillary mucinous neoplasm in 2 (6.5\%), and Gastric carcinoma in 1 (3.2\%). The 67 PDs (standard PD in 20 patients (29.9\%), SSPPD in 10 (14.9\%) and PPPD in 37 (55.2\%)) performed in group B

Table 1 Patient characteristics and laboratory data

\begin{tabular}{|c|c|c|c|}
\hline & $\begin{array}{l}\text { group } A \\
n=31\end{array}$ & $\begin{array}{l}\text { group B } \\
n=67\end{array}$ & $P$ value \\
\hline \multicolumn{4}{|l|}{ patient characteristics } \\
\hline Age (years) & $79.09 \pm 3.49$ & $61.69 \pm 6.37$ & $<.0001$ \\
\hline Gender & & & 0.14 \\
\hline male & 16 & 45 & \\
\hline female & 15 & 22 & \\
\hline Body mass index & $23.04 \pm 3.85$ & $22.82 \pm 3.84$ & 0.8 \\
\hline \multicolumn{4}{|l|}{ Comorbidity } \\
\hline Hypertension & 13 & 20 & 0.24 \\
\hline Hyperlipoproteinemia & 5 & 7 & 0.42 \\
\hline Diabetes mellitus & 5 & 12 & 0.83 \\
\hline Cardiac disease & 2 & 5 & 0.86 \\
\hline Plumonary disease & 1 & 1 & 0.57 \\
\hline Chronic renal disease & 1 & 0 & 0.14 \\
\hline cerebral disease & 0 & 3 & 0.23 \\
\hline Other & 1 & 0 & 0.14 \\
\hline \multicolumn{4}{|l|}{ Preoperative biliary drainage } \\
\hline Yes & 24 & 48 & 0.55 \\
\hline No & 7 & 19 & \\
\hline \multicolumn{4}{|l|}{ Diagnosis } \\
\hline Pancreatic adenocarcinoma & 8 & 31 & 0.08 \\
\hline Cholangiocarcinoma & 15 & 22 & \\
\hline Ampullary carcinoma & 5 & 3 & \\
\hline Intraductal papillary mucinous neoplasm & 2 & 4 & \\
\hline Duodenal carcinoma & 0 & 3 & \\
\hline Gastric carcinoma & 1 & 0 & \\
\hline Duodenal invasion of colon carcinoma & 0 & 1 & \\
\hline Other & 0 & 3 & \\
\hline \multicolumn{4}{|l|}{ Laboratory data } \\
\hline Hemoglobin & $12.20 \pm 1.81$ & $14.24 \pm 15.42$ & 0.46 \\
\hline Total bilirubin & $6.90 \pm 7.10$ & $4.85 \pm 5.01$ & 0.16 \\
\hline Amylase & $91.48 \pm 44.93$ & $153.48 \pm 234.91$ & 0.15 \\
\hline Hemoglobin A1C & $5.70 \pm 2.08$ & $6.29 \pm 2.03$ & 0.32 \\
\hline
\end{tabular}


included Pancreatic adenocarcinoma in 31 (46.3\%) patients, Cholangiocarcinoma in 22 (32.8\%), Intraductal papillary mucinous neoplasm in 4 (6.0\%), Ampullary carcinoma in 3 (4.5\%), Duodenal carcinoma in $3(4.5 \%)$, Duodenal invasion of colon carcinoma in 1 (1.5\%), and Other in 3 (4.5\%).

The mean surgical time in group A was $408.1 \pm 73.47$ min, which was significantly shorter than that in group $\mathrm{B}(\mathrm{P}=.04)$. Blood loss and blood transfusion were not significantly different between groups (Table 2).

\section{Pathologic results}

The American Joint Committee on Cancer (AJCC) cancer staging distribution was $4(13.3 \%)$ stage 0,9 (30\%) stage I, $16(54.3 \%)$ stage II, and $1(3.3 \%)$ stage III in group A and 2 (3.2\%) stage 0, 25 (39.1\%) stage I, 34 (53.7\%) stage II, and $3(6.7 \%)$ stage III in group B. The mean tumor size was $27.17 \pm 12.18 \mathrm{~mm}$ in group A and $30.59 \pm 13.64 \mathrm{~mm}$ in group $B(P=.25)$. The distribution of histological grades in group A was as follows: 12 (38.7\%) well differentiated, 9 (29\%) moderately differentiated, 4 (12.9\%) poorly differentiated, 3 (9.7\%) papillary, and 3 (9.7\%) other. In group B, it was as follows: 14 (21\%) well differentiated, 27 (40.6\%) moderately differentiated, $13(20 \%)$ poorly differentiated, 7 (10.7\%) papillary, and 6 (9.1\%) other (Table 3).

\section{Postoperative outcome}

The mean postoperative stay in group A was $25 \pm 16.46$ days, which was longer than that in group B (21.54 \pm 10.32 days), but the difference was not significant. One in-hospital death occurred in group A on postoperative day 22. There was no significant difference in mortality rate between group A and group B $(3.2 \%$ vs. $0 \%, \mathrm{P}=$ .14). The overall complication rate was $50.0 \%$ (54.8\% in group $\mathrm{A}$ and $46.3 \%$ in group $\mathrm{B} ; \mathrm{P}=.43)$. The most common complication was pancreatic fistula $(32.7 \%)$. The incidence of pancreatic fistula was similar in group A and group B ( $38.7 \%$ vs. $29.9 \%$, respectively; P $=.38$ ). There was also no significant difference in the occurrence of other complications: delayed gastric emptying, liver abscess, wound infection, intraabdominal bleeding, respiratory insufficiency, intraabdominal collection, sepsis, bile leakage, or gastrointestinal bleeding. There are summarized in Table 4.

\section{Long-term survival}

The mean follow up was 15.8 months in group A (median: 12.0 months; range, $0.8-65.4$ months) and 23.3 months in group B (median: 18.8 months; range, 1.3-59.5 months). The 1- and 3-year survival rates were $70.0 \%$ and $50.5 \%$, respectively, in group A and $84.8 \%$ and $65.9 \%$, respectively, in group B. There was no statistically significant difference between the two groups using the log-rank test $(\mathrm{P}=.10)$.

\section{Discussion}

There have been many cases of PD since the first report by Wipple et al. in 1935 [13]. However, the incidence of postoperative complications is still $30 \%-60 \%[14-16]$. PD may cause considerable complications, including pancreatic fistula, intra-abdominal bleeding, intra-abdominal

Table 2 Operative outcomes

\begin{tabular}{|c|c|c|c|c|}
\hline & & $\begin{array}{l}\text { group } A \\
n=31\end{array}$ & $\begin{array}{l}\text { group B } \\
n=67\end{array}$ & $P$ value \\
\hline \multicolumn{5}{|l|}{ Type of pancreaticoduodenectomy } \\
\hline & PPPD & 18 & 37 & 0.44 \\
\hline & SSPPD & 7 & 10 & \\
\hline & PD & 6 & 20 & \\
\hline \multicolumn{5}{|l|}{ Pancreatic texture } \\
\hline & soft & 26 & 47 & 0.04 \\
\hline & hard & 5 & 27 & \\
\hline Tumor size (mm) & & $27.17 \pm 12.18$ & $30.59 \pm 13.64$ & 0.25 \\
\hline Pancreatic duct diameter (mm) & & $3.61 \pm 3.03$ & $4.03 \pm 2.94$ & 0.58 \\
\hline \multicolumn{5}{|l|}{ Pancreatic drainage } \\
\hline & internal & 12 & 28 & 0.77 \\
\hline & external & 19 & 39 & \\
\hline Surgical time (min) & & $408.1 \pm 73.47$ & $461.76 \pm 84.98$ & 0.003 \\
\hline Blood loss (ml) & & $948.58 \pm 468$ & $1225.5 \pm 925.82$ & 0.12 \\
\hline Blood transfusion (ml) & & $209.33 \pm 425.62$ & $231.64 \pm 510.57$ & 0.84 \\
\hline \multicolumn{5}{|l|}{ Portal vein resection } \\
\hline & Yes & 1 & 8 & 0.16 \\
\hline & No & 30 & 59 & \\
\hline
\end{tabular}

$\mathrm{PD}=$ pancreaticoduodenectomy SSPPD = substomach preserving pancreaticoduodenectomy; PPPD = pylorus preserving pancreaticoduodenectomy. 
Table 3 Pathological results

\begin{tabular}{|c|c|c|c|}
\hline & $\begin{array}{l}\text { group } A \\
\mathrm{n}=31\end{array}$ & $\begin{array}{l}\text { group B } \\
n=67\end{array}$ & $P$ value \\
\hline AJCC T stage & & & 0.28 \\
\hline is & 4 & 2 & \\
\hline 1 & 3 & 11 & \\
\hline 2 & 10 & 16 & \\
\hline 3 & 12 & 32 & \\
\hline 4 & 1 & 3 & \\
\hline AJCC Nodal status & & & 0.87 \\
\hline NO & 16 & 33 & \\
\hline N1 & 14 & 31 & \\
\hline AJCC Stage & & & 0.34 \\
\hline 0 & 4 & 2 & \\
\hline $\mathrm{IA}$ & 1 & 9 & \\
\hline IB & 8 & 16 & \\
\hline$\| \mathrm{A}$ & 3 & 6 & \\
\hline$\| B$ & 12 & 27 & \\
\hline III & 1 & 2 & \\
\hline Grade of neoplasm & & & 0.43 \\
\hline well & 12 & 14 & \\
\hline moderately & 9 & 27 & \\
\hline poorly & 4 & 13 & \\
\hline papillary & 3 & 7 & \\
\hline other & 3 & 6 & \\
\hline
\end{tabular}

AJCC $=$ The American Joint Committee on Cancer abscess, sepsis and organ failure, and requires highquality techniques and management methods in the perioperative period. Though PD is performed in many hospitals, its associated morbidity and mortality rates are high. However, the rate of morbidity and mortality associated with PD has decreased, especially in highvolume centers [6-8]. Complications tend to be lower in institutions that perform more than a certain number of surgeries and have more than a certain number of staff medical specialists; such institutions provide better management of complications, which provides the strength of the recommendation. It was suggested that PD was contraindicated in most elderly patients, because such aggressive surgery would result in perioperative complications. Yeo et al [17] noted that age appears to be an important predictor of death in low-volume centers but not in high-volume centers. Several studies reported that age was not an independent risk factor for perioperative mortality and morbidity following PD $[11,18]$. Since PD is the only chance these patients have for a cure, we suggest that PD is justified, even in the elderly. If appropriate management of elderly patients is provided, the safety of perioperative management will be secured in high-volume centers. Therefore, it has been reported that patients should not be excluded from PD due to age [10].

In our institution, we also investigated the safety of elderly patients following PD. Patients aged 75 years and

Table 4 Postoperative outcomes

\begin{tabular}{|c|c|c|c|}
\hline & group $\mathrm{A}$ & group B & $P$ value \\
\hline & $\mathrm{n}=31$ & $\mathrm{n}=67$ & \\
\hline \multicolumn{4}{|l|}{ Complications } \\
\hline \multirow[t]{4}{*}{ Pancreatic fistula } & 12 & 20 & 0.38 \\
\hline & Grade A 5 & 5 & \\
\hline & Grade B 6 & 15 & \\
\hline & Grade C 1 & 0 & \\
\hline Delayed gastric emptying & 2 & 4 & 0.93 \\
\hline Liver abscess & 0 & 1 & 0.49 \\
\hline Bowel obstruction & 0 & 0 & 1 \\
\hline Wound infection & 5 & 5 & 0.19 \\
\hline Intraabdominal bleeding & 1 & 2 & 0.95 \\
\hline Respitory insufficiency & 4 & 3 & 0.13 \\
\hline Intraabdominal collection & 3 & 3 & 0.32 \\
\hline Sepsis & 1 & 0 & 0.14 \\
\hline Bile leakage & 1 & 0 & 0.14 \\
\hline Gastrointestinal bleeding & 0 & 1 & 0.49 \\
\hline \multicolumn{4}{|l|}{ Postoperative outcomes } \\
\hline Postoperative hospital stay (day) & $25 \pm 16.46$ & $21.54 \pm 10.32$ & 0.22 \\
\hline Mortality & 1 & 0 & 0.14 \\
\hline Morbidity & 17 & 31 & 0.43 \\
\hline
\end{tabular}


older (group A) had remarkably similar outcomes compared to younger patients (group B), with no differences in patient characteristics and preoperative laboratory data, excluding albumin. Moreover, there was no difference in morbidity and mortality between groups. The mean surgical time for group A was significantly shorter than that for group $B(P<0.01)$. It was suggested that this was because a portal vein resection was done for only 1 of 31 patients (3.2\%) in group A, which was less than that done in group B (11.9\%), although this difference was not significant. Pancreatic fistula is the most threatening complication of PD. In the literature, the rates of pancreatic fistula range from $5 \%$ to $40 \%[2-5]$. In the present study, the incidence of pancreatic fistula was similar between older and younger patients $(45.1 \%$ vs. $29.9 \%$, respectively; $\mathrm{P}=.14$ ), though there was a tendency for increased normal pancreatic texture (soft pancreas) in older patients $(\mathrm{P}=.04)$. Several reports compared external drainage and no-stent procedures and found that the incidence of fistula was significantly lower for external drainage $[3,19]$. The normal pancreas preserves exocrine function, and its main pancreatic duct is narrow. Thus, one cannot rule out the possibility of injury during surgical manipulation. The diameter of the pancreatic duct is approximately $1-2 \mathrm{~mm}$ in the normal pancreas, and postoperative swelling can develop temporarily that can result in stenosis. Thus, stent placement is considered essential at our institution. It is thought that placement of an external drain can minimize the leakage from a branch of remnant pancreatic duct. The external drain reduces the stress at the anastomotic site by a pressure gradient and minimizes the outflow into the branch of the pancreatic duct. We placed an external drain for the normal pancreas. We suggest that an external drain reduces the incidence of pancreatic fistula in a normal pancreas.

Older patients also had similar lengths of postoperative hospital stay compared with younger patients. The rate of overall survival in older patients tended to be lower compared with younger patients, though the difference was not statistically significant. Recently, most patients with pancreatic carcinoma receive adjuvant chemotherapy [20]. It is difficult to compare older and younger patients, as we did not manage some older patients after surgery, because we considered the side effects of chemotherapy due to their age, especially for those over 80 years of age. Aloia et al report delayed recovery after PD [21]. Because patient age was independently associated with a decreased likelihood of receiving adjuvant therapy by multivariate analysis, we suggest that it might be better to avoid adjuvant chemotherapy after surgery for elderly patients. Except for this matter, our data showed no significant differences in postoperative morbidity and mortality between older and younger PD patients.
The results of several series [22-26] suggest that age is unrelated to morbidity and mortality and that PD can be performed safely if it is provided by appropriate indication and management. Our study also addresses the safety of PD management in elderly patients and supports these opinions.

\section{Conclusion}

In conclusion, it cannot be ignored that the elderly population is getting larger. We must investigate the management of elderly patients after PD and prepare further for more experiences of PD. If appropriate surgical management is provided to elderly patients, we suggest that PD will lead to no adverse effects after surgery, and PD can be performed safely in elderly patients. We conclude that age should not be a contraindication to PD.

\section{Author details}

${ }^{1}$ Department of Surgery, Saiseikai Yokohamashi Tobu Hospital, 3-6-1 Shimosueyoshi, Tsurumi-ku, Yokohama-shi, Kanagawa, 230-0012 Japan. ${ }^{2}$ Department of Surgery, Keio University School of Medicine, 35 Shinanomachi, Shinjuku-ku, Tokyo, 160-8582 Japan.

\section{Authors' contributions}

Yl designed methods and carried out the instructions, analyzed the data, interpreted the results and drafted the manuscript. All authors read and approved the final manuscript.

\section{Competing interests}

The authors declare that they have no competing interests.

Received: 20 July 2011 Accepted: 11 September 2011

Published: 11 September 2011

\section{References}

1. Eiseman B: Surgical decision making and elderly patients. Bull Am Coll Surg 1996, 81:8-11, 65.

2. Lowy AM, Lee JE, Pisters PW, Davidson BS, Fenoglio CJ, Stanford P, Jinnah R, Evans DB: Prospective, randomized trial of octreotide to prevent pancreatic fistula after pancreaticoduodenectomy for malignant disease. Ann Surg 1997, 226:632-641.

3. Roder JD, Stein HJ, Bottcher KA, Busch R, Heidecke CD, Siewert JR: Stented versus nonstented pancreaticojejunostomy after pancreatoduodenectomy: a prospective study. Ann Surg 1999, 229:41-48

4. Cameron JL, Pitt HA, Yeo CJ, Lillemoe KD, Kaufman HS, Coleman J: One hundred and forty-five consecutive pancreaticoduodenectomies without mortality. Ann Surg 1993, 217:430-435, discussion 435-438.

5. Montorsi M, Zago M, Mosca F, Capussotti L, Zotti E, Ribotta G, Fegiz G, Fissi S, Roviaro G, Peracchia A, et al: Efficacy of octreotide in the prevention of pancreatic fistula after elective pancreatic resections: a prospective, controlled, randomized clinical trial. Surgery 1995, 117:26-31.

6. Gordon TA, Burleyson GP, Tielsch JM, Cameron JL: The effects of regionalization on cost and outcome for one general high-risk surgical procedure. Ann Surg 1995, 221:43-49.

7. Sosa JA, Bowman HM, Gordon TA, Bass EB, Yeo CJ, Lillemoe KD, Pitt HA, Tielsch JM, Cameron JL: Importance of hospital volume in the overall management of pancreatic cancer. Ann Surg 1998, 228:429-438.

8. Lieberman MD, Kilburn H, Lindsey M, Brennan MF: Relation of perioperative deaths to hospital volume among patients undergoing pancreatic resection for malignancy. Ann Surg 1995, 222:638-645.

9. Sohn TA, Yeo CJ, Cameron JL, Lillemoe KD, Talamini MA, Hruban RH, Sauter PK, Coleman J, Ord SE, Grochow LB, et al: Should 
pancreaticoduodenectomy be performed in octogenarians? I Gastrointest Surg 1998, 2:207-216.

10. Brozzetti S, Mazzoni G, Miccini M, Puma F, De Angelis M, Cassini D, Bettelli E, Tocchi A, Cavallaro A: Surgical treatment of pancreatic head carcinoma in elderly patients. Arch Surg 2006, 141:137-142.

11. Makary MA, Winter JM, Cameron JL, Campbell KA, Chang D, Cunningham SC, Riall TS, Yeo CJ: Pancreaticoduodenectomy in the very elderly. J Gastrointest Surg 2006, 10:347-356.

12. Scurtu R, Bachellier P, Oussoultzoglou E, Rosso E, Maroni R, Jaeck D: Outcome after pancreaticoduodenectomy for cancer in elderly patients. J Gastrointest Surg 2006, 10:813-822

13. Whipple AO, Parsons WB, Mullins CR: Treatment of Carcinoma of the Ampulla of Vater. Ann Surg 1935, 102:763-779.

14. Suc B, Msika S, Piccinini M, Fourtanier G, Hay JM, Flamant $Y$, Fingerhut A, Fagniez PL, Chipponi J: Octreotide in the prevention of intra-abdominal complications following elective pancreatic resection: a prospective, multicenter randomized controlled trial. Arch Surg 2004, 139:288-294, discussion 295.

15. Conlon KC, Labow D, Leung D, Smith A, Jarnagin W, Coit DG, Merchant N, Brennan MF: Prospective randomized clinical trial of the value of intraperitoneal drainage after pancreatic resection. Ann Surg 2001 234:487-493, discussion 493-484.

16. Yeo CJ, Cameron JL, Lillemoe KD, Sohn TA, Campbell KA, Sauter PK, Coleman J, Abrams RA, Hruban RH: Pancreaticoduodenectomy with or without distal gastrectomy and extended retroperitoneal lymphadenectomy for periampullary adenocarcinoma, part 2: randomized controlled trial evaluating survival, morbidity, and mortality. Ann Surg 2002, 236:355-366, discussion 366-358.

17. Yeo CJ, Cameron JL, Sohn TA, Lillemoe KD, Pitt HA, Talamini MA, Hruban RH, Ord SE, Sauter PK, Coleman J, et al: Six hundred fifty consecutive pancreaticoduodenectomies in the 1990s: pathology, complications, and outcomes. Ann Surg 1997, 226:248-257, discussion 257260.

18. Gouma DJ, van Geenen RC, van Gulik TM, de Haan RJ, de Wit LT, Busch OR, Obertop H: Rates of complications and death after pancreaticoduodenectomy: risk factors and the impact of hospital volume. Ann Surg 2000, 232:786-795.

19. Poon RT, Fan ST, Lo CM, Ng KK, Yuen WK, Yeung C, Wong J: External drainage of pancreatic duct with a stent to reduce leakage rate of pancreaticojejunostomy after pancreaticoduodenectomy: a prospective randomized trial. Ann Surg 2007, 246:425-433, discussion 433-425.

20. Burris HA, Moore MJ, Andersen J, Green MR, Rothenberg ML, Modiano MR, Cripps MC, Portenoy RK, Storniolo AM, Tarassoff P, et al: Improvements in survival and clinical benefit with gemcitabine as first-line therapy for patients with advanced pancreas cancer: a randomized trial. J Clin Oncol 1997, 15:2403-2413.

21. Aloia $T A$, Lee JE, Vauthey JN, Abdalla EK, Wolff RA, Varadhachary GR, Abbruzzese JL, Crane CH, Evans DB, Pisters PW: Delayed recovery after pancreaticoduodenectomy: a major factor impairing the delivery of adjuvant therapy? J Am Coll Surg 2007, 204:347-355.

22. de Franco V, Frampas E, Wong M, Meurette G, Charvin M, Leborgne J, Regenet N: Safety and feasibility of pancreaticoduodenectomy in the elderly: a matched study. Pancreas 2011, 40:920-924

23. Hatzaras I, Schmidt C, Klemanski D, Muscarella P, Melvin WS, Ellison EC, Bloomston M: Pancreatic resection in the octogenarian: a safe option for pancreatic malignancy. J Am Coll Surg 2011, 212:373-377.

24. Lee MK, Dinorcia J, Reavey PL, Holden MM, Genkinger JM, Lee JA, Schrope BA, Chabot JA, Allendorf JD: Pancreaticoduodenectomy can be performed safely in patients aged 80 years and older. J Gastrointest Surg 2010, 14:1838-1846.

25. Khan S, Sclabas G, Lombardo KR, Sarr MG, Nagorney D, Kendrick ML, Donohue JH, Que FG, Farnell MB: Pancreatoduodenectomy for ductal adenocarcinoma in the very elderly; is it safe and justified? J Gastrointest Surg 2010, 14:1826-1831.

26. Tani M, Kawai M, Hirono S, Ina S, Miyazawa M, Nishioka R, Shimizu A, Uchiyama $\mathrm{K}$, Yamaue $\mathrm{H}$ : A pancreaticoduodenectomy is acceptable for periampullary tumors in the elderly, even in patients over 80 years of age. J Hepatobiliary Pancreat Surg 2009, 16:675-680. doi:10.1186/1477-7819-9-102

Cite this article as: Ito et al:: The impact of surgical outcome after pancreaticoduodenectomy in elderly patients. World Journal of Surgical Oncology 2011 9:102.

\section{Submit your next manuscript to BioMed Central and take full advantage of:}

- Convenient online submission

- Thorough peer review

- No space constraints or color figure charges

- Immediate publication on acceptance

- Inclusion in PubMed, CAS, Scopus and Google Scholar

- Research which is freely available for redistribution

Submit your manuscript at www.biomedcentral.com/submit
Biomed Central 